\section{Dietas com Restrição de Iodo (DRI)}

\section{RESUMO}

No contexto do manuseio do câncer diferenciado de tireóide com ${ }^{131}$, faz-se histórico e descrição das dietas com restrição de iodo (DRI). Elabora-se DRI mais abrangente e auto-explícita. Expõem-se mecanismos de aumento de captação pelas DRI, baseados na expoliação de iodo. Comprova-se a eficácia das DRI em favorecer expoliação e rastreamento; o possivel benefício quanto a dose ablativa; não ter-se demonstrado efeito em dose terapêutica, quiçá por insuficiente pesquisa; a importância de obter iodúria inferior a $50 \mathrm{ug} /$ dia ou $50 \mathrm{ug} / \mathrm{g}$ creatinina, para prevenir contaminação e avaliar a eficácia $e$ adesão a DRI. Diante da excessiva ingestão de iodo nos EUA, Reino Unido e países asiáticos, com resultante queda na atividade iodocaptante, deplora-se a escassa adoção de DRl, em relatos de centros de pesquisa, cuja credibilidade só é sustentável, admitindo-se tácita prescrição de DRI informal, raramente constando em "Materiais e Métodos". Outrossim, condena-se o aumento de dose de ${ }^{131}$, na contaminação: a rápida expoliação de iodo por DRl é eficiente e inócua. Comenta-se a inexistência de DRI publicada no Brasil, duvidando-se de sua necessidade, face à deficiência endêmica de iodo, em algumas regiōes. O desconhecimento de seu conteúdo, e de eventual excesso, em alguns alimentos, conduz o autor a elaborar algoritmo: 1. Avaliação de quota de iodo alimentar das populações, ou 2. Exclusão de contaminação, pela medida da iodúria, ou 3. Prescrição de DRI. O autor propõe o axioma: "A DRI pode às vezes não ser benéfica, a contaminação é sempre maléfica". (Arq Bras Endocrinol Metab 1998:42/6:461-477)

Unitermos: Neoplasias da tireóide; Radioisótopos de iodo; lodo/Administração e dosagem; Deficiência de iodo; lodo/Urina

\footnotetext{
ABSTRACT

In the context of differentiated thyroid cancer management with radioiodine, a gradual description of low iodine diets (LIDS) is undertaken. A more ample and autoexplicit one is reported, as well as the mechanisms of uptake increase, based on iodine depletion. The efficiency of LIDs in favoring iodine depletion and scanning, as potentially useful for ${ }^{131} \mid$ ablation, but unseftled for ${ }^{131}$ i treatment, is examined under the distress of wanting research on the subject. The usefulness of urinary iodine assay to avoid contamination, to appraise adherence to, and efficiency of LIDs, is stressed. In face of increased intake of iodine in the USA, UK and Pacific regions, it is to regret the scarce LID adoption in reports, whose credibility stands only on the belief of tacit informal LID prescription, rarely inserted in "Material and Methods". It is disapproved too the increase in ${ }^{131}$ dose, in case of contamination, since quick depletion of lodine by LID is harmless and efficient. As there is an endemic deficiency of iodine in some regions, it is to doubt the need of LID in Brazil, where no one has been published. Nevertheless, as neither the iodine content of foods, nor the existence of fortuitous excess in some foods are known, the author dares to suggest the
}

\section{perspectivas}

\author{
Henry Wolff
}

Disciplina de Endocrinologiae Nutrologia, Fundacão Faculdade Federal de Ciências Médicas de Porto Alegre (FFFCMPA) e Serviço de Medicina Nuclear do Hospital Moinhos de Vento, Porto Alegre, RS 
following algorithm: 1. To estimate populations food iodine content, or 2. To obviate contamination, by urinary iodine assay, or 3 . To prescribe a LID. The author presents the axiom: "Maybe LIDs are sometimes unhelpful, contamination is always harmful."

(Arq Bras Endocrinol Metab 1998:42/6:461-477)

Keywords: Thyroid neoplasms: lodine radioisotopes; lodine-Administration and dosage; lodine deficiency: lodine-Urine.

\section{Dietas com Restrição de Iodo (DRI)*}

\section{INTRODUÇĀO E HISTÓRICO}

No tratamento inicial do carcinoma diferenciado da tireóide*, excetuados os casos de menor risco, a maioria dos autores recomenda tireoidectomia total $(1,2)$, com tentativa de remoção completa do tumor. Se, no rastreamento pós-operatório, são demonstrados restos de tireóide* ${ }^{*}$ é predominante a prescrição de dose ablativa *, na faixa de 30 a $150 \mathrm{mCi}$, seguida de tratamento supressivo* (2-6). Entretanto, se dose terapêutica * é indicação unânime (2,7-9), alguns julgam com ceticismo a dose ablativa (9-11). Esta tem por fim evitar competição pelo 131I, visto ser o tumor menos ávido pelo iodo (12). No estado de hipotireoidismo que se observa, à suspensão do tratamento supressivo, a elevação do TSH endógeno estimula a atividade iodocaptante do tumor e de restos de tireóide. Mais recentemente, vem se testando com promissora expectativa (13), o TSH humano recombinante, que evita o prolongado hipotireoidismo necessário para elevar o TSH endógeno (14-19).

Três objetivos são visados ao uso do ${ }^{131}$ I deteç̧ão do tumor e de restos de tireóide, ablação destes, c destruição de tumor inoperável, com doses altas do radioisótopo, enquanto se detecte significativa atividade iodocaptante. A principal restrição é o efeito cumulativo da radiação corporal total sobre o sistema

\footnotetext{
* Terminologia [modificada de Maxon e Smith, (24)]:Dieta com Restrição de Iodo (DRI): Dicta contendo nào mais que $50 u g$ ao dia de iodo, que resulte cm iodo urinário (iodúria) $\leq 50 \mathrm{ug} / \mathrm{dia}$ ou $\leq 50 \mathrm{ug} / \mathrm{g}$ creatinina. Contaminação: Excesso de I-127 exógeno. Carcinoma ou Câncer diferenciado da tircóide: Refere-sc a carcinomas papilar (incluindo o misto) a folicular. Restos de tiréide: Tecido tireóideo macroscopicamente normal, remanescente após tireodectomia. Tumor residual: o que persiste, na linha de resseção cirúrgica ou dentro de $2 \mathrm{~mm}$ desta, após tireodectomia. Pode ser microscópico ou macroscópico (aparente para o cirurgiäo). Tumor recorrente ou recidiva: o que recorre no pescogo, após intervalo presumido livere de doença. Metástase ganglionar: metástase em linfonodo cervical ou supraclavicular Metástase distante: metástasc fora do pescogo. Rastreamento corporal: 131 I para revelar restos de tircóide c/ou tumer persistente. Dose ablativa: 13l I para destruir restos de tircóide. Dose terapéuntica: l3 I I para destruir tumor residual, recorrentc c/ou metastático. Tratamento supressivo: hormônio tircóideo, em dose que suprime a secreșío de TSI.
}

hematopoiético $(12,20,21)$, e o limite a respeitar na radiação para o pulmão, no caso de extensas metástases pulmonares $(21,22)$. Mesmo na auséncia de atividade iodocaptante localizada, tem-se administrado ${ }^{131}$ I em altas doses, quando a tireoglobulina sérica está elcvada $(18,23)$.

Em 1942, Keston e cols relataram deposição de iodo radioativo em metástase de carcinoma de tircóide (25). O primeiro tratamento exitoso relatou-se em $1946(26)$.

Desde então, foi crescente o número de pacientes tratados, ultrapassando 5.000 antes dos anos 80 (27). Uma constante preocupação tem sido a limitada captação do ${ }^{131}$ I pelo tumor (28). A recomendação de evitar pescados e iodo exógeno não tem eficácia rclatada (29). TSH bovino é freqüentemente desapontador e promove liberação de 131 I (28). Além disso, pode estimular crescimento do tumor e metástases (30). Por isso, novas alternativas foram buscadas.

Em relato preliminar, demonstrou-se em 1966, no tratamento do carcinoma de tireóide, aumento da captação de ${ }^{131}$ I com emprego de manitol endovenoso (31), tendo por base o efeito de expoliação aguda de iodo, em aumentar em duas a três vezes, a captação deste pelas células tireóideas (32). Barakat e Ingbar (32), utilizando manitol como diurético, fizeram o primeiro relato de dieta com restrição de iodo (DRI), consistindo de leite desiodado (acrescido de café preto, chocolate, baunilha) c água destilada. Em 1969, Hamburger (28) relatou emprego de manitol EV e de ácido etacrínico oral, junto a $12 \mathrm{~g}$ de cloreto de sódio e $4000 \mathrm{ml}$ de água, via oral, em 25 pacientes com câncer inoperável de tircóide. Associon DRI bastante simples e monótona, contendo alegadamente 20 a $25 \mathrm{ug}$ de iodo, ao dia. Observou aumento de 2 a 3 vezes na captação de $131 \mathrm{I}$, en 7 dos 9 casos tratados com manitol e 9 dos 16 tratados com ácido etacrínico, resultados assim similares, com as duas drogas. Como o uso do manitol é trabalhoso e desagradável, requer hospitalização c pode provocar arcadas c vômitos, Hamburger sugeriu manter apenas o uso do ácido etacrínico, mais simples e aceitável. Entretanto, um paciente desenvolveu anemia aplástica transitória, após este último (28). Em 1981, Beyer e cols demonstraram o potente efeito estimulador da hidroclorotiazida sobre a depuração renal do iodo, no cão (33). Em 1984, Maruca e cols (34) estudaram o uso de hidroclorotiazida ou furosemida, associadas a $12 \mathrm{~g}$ de $\mathrm{NaCl}$ e 3 litros de água diários, junto à DRI de Hamburger (28). Demonstraram aumento médio de $146 \%$ na captação de 131I no tumor. Contudo, houve decréscimo de $56 \%$ na depuração renal e retardada desaparição 
plasmática do ${ }^{131} \mathrm{I}$, resultando em aumento de $68 \%$ na radiação corporal total, por $150 \mathrm{mCi}$ de ${ }^{131} \mathrm{I}$ administrados. Quando corrigido pelo aumento de radiação corporal total, o aumento na radiação na lesão, relativa ao aumento da irradiação corporal total, foi de apenas $46 \%$, em média (34). Os autores analisam os mecanismos aventados para explicar o aumento de 2 a 3 vezes na captação de ${ }^{131} \mathrm{I}$ em lesões, com regimes até então descritos $(28,31,32)$, citando o aumento da relação ${ }^{131}$ I $/{ }^{127}$ I corporal e o aumento intrínseco na captação de iodo pelo tecido tireóideo, induzidos pela expoliação aguda do iodo (32). Acrescem a redução na depuração renal do ${ }^{131} \mathrm{I}$, como possível tercciro mecanismo, resultante quiçá de expoliação de sódio e contração de volume líquido extracelular, originando retardo no tempo de desaparição plasmática do 131 I. Concluem que a DRI, associada a diuréticos, não tem a eficácia apregoada (34). Em surpreendente estudo anterior, Goslings (35) não verificou diferença na expoliação de iodo, entre 7 pacientes submetidos a DRI, e 7 submetidos à mesma dieta acrescida de ácido etacrínico. Refutou o favorecimento da expoliaçăo de iodo extracclular, pelo ácido etacrínico, assim se opondo à conclusão de Hamburger (28). Aliás, demonstrou duplicação na dose tumoral do $131 \mathrm{I}$, apenas com a DRI. Os regimes que incluem diurético foram abandonados, em favor do uso isolado da dieta. Em 1983 e 1988, foram respectivamente publicadas as DRI de Maxon c cols (36) e Lakshmanan e cols (29), hoje as mais citadas, pelo menos na literatura americana. Em 1994, Ain e cols (37) propuseram dieta por sonda, em casos de invasão do esôfago, pelo tumor.

Mau grado a afirmativa de Hamburger (28) de que, ainda quando seja alta a captação de ${ }^{131} \mathrm{I}$, considere-se a preparação com diuréticos (que inclui DRI, segundo ele), na esperança de reduzir a dose total de ${ }^{131} \mathrm{I}$, a recomendação para uso rotineiro destas dietas foi omitida durante muito tempo. Reservava-se aos casos de muito baixa captação de ${ }^{131}$ I (12), essencial na contaminação. Isto ocorreu, na década de $70, \mathrm{com}$ paciente nossa, para a qual, o generalista que a enviou para tratamento com ${ }^{131} \mathrm{I}$, prescreveu, às vésperas, iodeto de potássio, para infeç̧ão respiratória. Àquela época, constituía um transtorno, após tireoidectomia total, deparar com tumor destituído de atividade iodocaptante, em decorrência quiçá, de contaminação, pois impunha DRI monótona e impalatável $(28,31)$. Como então, até hoje é ainda muito difundido o conceito do uso apenas excepcional de DRI. Uma série de dados e considerações, todavia, compeliam ao uso de rotina, tal o conceito de que, quanto maior a atividade iodocaptante, maior a eficácia no manuseio do ${ }^{131} \mathrm{I}$ e menor o risco de exposição cumulativa (20). Além disso, demonstrou-se que a DRI, por si, eleva a captação e a dose de radiação de modo significativo (35). Quiçá mais premente, tenha sido a crescente quota de iodo, na dieta dos americanos (38-41), decorrente do elevado teor em certos alimentos (41-50) e espelhada na queda da captação de radioiodo pela tireóide (3941,51-53). Na ausência de contaminação, a captação, pela tireóide normal, é inversamente relacionada ao nível crônico de ingestão de iodo $(38,40,51,54-56)$. $\mathrm{Em}$ contraposiçăo, havia-se verificado o efeito da expoliação destc, na atividade iodocaptante do carcinoma de tireóide $(28,29,31,34,35)$. Com efeito, desde os anos 80 , têm surgido publicações recomendando o uso de rotina $(23,29,36,57,58)$, ainda que tal não se verifique na maioria das publicaçōes. A literatura atinente será abordada em "Problema da Adoção das DRI". Com base nos trabalhos de Lakshmanan e cols (29) e Maxon e cols (36), o autor elaborou DRI $\mathrm{cm}$ português, face à inexistência, no Brasil, de dieta palatável c variada, para recomendação aos pacientes. Ela será descrita em "Dicta Adatada pelo Autor".

\section{AS DRI EXISTENTES}

Além da simples recomendação de evitar pescados e iodo exógeno (59), ainda praticada em muitas clínicas, somente na década de 60 , surgiu dieta precisa, proposta por Hamburger (28), e, por anos, a única citada na literatura. Em 1983, Maxon e cols publicaram excelente regime, agrupando os alimentos em 6 categorias (36). Mazzaferri (58), em 1986, indicava como rotina restrição do iodo, por uma semana, precedendo rastreamento e dose terapêutica. Baseava-se nos dados de Kidd e cols (45). Em 1988, considerando complicada a dieta de Maxon e cols (36), Lakshmanan e cols relataram um regime bastante simplificado, com igual eficácia (29). As dietas de Hamburger (28), Maxon (36) c Lakshmanan (29) serăo analisadas abaixo. Como complemento, acrescenta-se a dieta por sonda de Ain e cols (37). Excluem-se dietas não avaliadas, como a de Harbert (6).

\section{Dieta de Hamburger (28)}

Recomendada para cinco dias de tratamento e mais variada que a precedente (31), incluía carne magra de boi e vitela; lake trout (peixe de água doce, Salvelinus namaycush, dos Grandes Lagos, EUA, quiçá inexistente no Brasil); crvilha; couve-flor; tomate fresco; cebola; pepino; alface; maçã e pêra frescas, laranja, arroz, batatas cozidas, 1 ou 2 copos de leite, água, café e chocolate [nesta ordem, no original (28)]. Além de 
diurético, incluíam-se $12 \mathrm{~g}$ de cloreto de sódio e $4000 \mathrm{ml}$ de água via oral ao dia. Proposta para fornecer 20 a 25 ug de iodo, chama a atenção não haver reparos quanto ao iodo contido no sal de cozinha [já que há muito vem se fazendo sua suplementação com iodeto de potássio, nos EUA (60)]. Os resultados obtidos pelo emprego deste regime, assim como do anterior de Hamburger e Desai (31), no que tange ao aumento de captação de ${ }^{131}$ I e ao efeito terapêutico, serão abordados em "Eficácia das DRI". O presente autor pode testemunhar os protestos dos pacientes, quanto à impalatabilidade do regime e o mal estar pelo uso de diurético, sal de cozinha e água. Há muito, não se registra sua utilização, na literatura.

\section{Dieta de Maxon e cols (36)}

Com o desígnio de contrapor-se ao excesso de iodo alimentar e ser seguida por uma semana, antes da administração do $131 \mathrm{I}$, tem conteúdo fixo calórico (1440 Kcal) e de macronutrientes (HdeC:144g, P: $54 \mathrm{~g}, \mathrm{~L}: 65 \mathrm{~g}$ ) para fornecer $45-50 \mathrm{ug}$ de iodo ao dia. $\hat{E}$ restrição significativa, face à ingestão usual de americanos de 240 a 740 ug ao dia $(39,40)$. Mas, não preenche as recomendações dictéticas de alguns nutrientes e calorias, só se justificando pelo breve período de sete dias de utilização (36). Os autores estabeleceram 6 listas de alimentos, a saber: l. Vegetais (onde incluem verduras, saladas, legumes, algumas leguminosas e tubérculos) 2.Pão (abrangendo pãcs, cereais, massas) 3. Frutas (com as quantidades equivalentes) 4.Carmes, compreendendo boi, vitela, porco fresco, cordeiro, peixes de água doce, manteiga de amendoim baixa em sódio, com exclusão de, ovos 5.Lacticínios (que são excluídos) e gorduras (contendo margarina e manteiga, ambas sem sal, óleos vegetais, óleos com e sem vinagre, torresmo casciro). 6.Diversos (incluindo açúcar, balas de goma não vermelhas, marchmelo, café e chá não solúveis, gelatina com fruta ou suco permitido, sal não iodado). Permitem quatro, duas e cinco porções, nas listas 1 a 3 , respectivamente. $\mathrm{Na}$ lista da carne, permitem duas porções de 100 gramas. Permitem quantidades ilimitadas de gorduras da lista e, dos diversos, duas porções ao dia. Em cada lista, anutam recomendações suplementares e omissões a serem feitas. O presente autor fez uma adatação modificada, das listas e respectivas recomendações, na seção: "Dicta Adatada pelo Autor", onde as omissões e limitações foram anotadas. Maxon e cols apresentam aos interessados, um exemplo de menu para um dia da dieta. Exceto ser enfadonha, a dieta não provocoul para-efeitos (36).

\section{Dieta de Lakshmanan e cols (29)}

Foi também proposta levando em conta a elevada quota de iodo na dieta, nos EUA, e os resultados favoráveis relatados com regimes de expoliação, na avaliação/tratamento de tumores da tireóide, com ${ }^{131}$ I planejada para fornecer $50 u g$ de iodo ao dia e reduzir a excreção urinária para $50 \mathrm{ug} /$ grama de creatinina, teve como objetivo fundamental a simplicidade e facilidade de seguimento, em oposição à dieta de Maxon e cols (36). Os autores avaliaram-na em 5 pacientes atireóticos, que a seguiram por quatro semanas, as duas primciras, associada à triiodotironina; as duas últimas precederam o rastreamento com l31 I (29). Entretanto, na rotina, recomenda-se usá-la após a suspensão da triiiodotironina, nas duas semanas que precedem o rastreamento/tratamento. A dieta, livre do ponto de vista calórico e de escolha de alimentos, resume-se a 7 proibições alimentares e 3 recomendações adicionais. Os alimentos a evitar foram: 1. Sal iodado, sal marinho; 2. Lacticínios; 3. Ovos; 4. Alimentos marinhos; 5. Pão preparado com condicionadores iodados; 6. Alimentos e medicamentos com corantes vermelhos; 7. Alimentos não caseiros. A primeira recomendação refere-se à necessidade de inspeção de rótulos dos alimentos; a segunda, aos cuidados com alimentos de restaurantes, e a terceira, com o pigmento vermelho $n^{\mathrm{Q}} 3$, usado em alimentos e medicamentos. Detalhes podem ser consultados ma seção: "Dieta Adatada pelo Autor".

\section{Dieta de Ain e cols (37)}

Destina-se a pacientes com disfagia decorrente de carcinoma tireóideo invasivo do esôfago, que necessitam receber ${ }^{131}$ I para diagnóstico ou tratamento. Relatam caso $\mathrm{em}$ que obtiveram, em 15 dias, redução do indo urinário de 378 para 13 ug ao dia. Utilizam ingredientes comerciais correntes, liquidificados a domićlio.

\section{Dieta Adatada pelo Autor}

Para prescrever dieta apropriada a nosso meio, decidiu o autor aliar a simplicidade e facilidade de Lakshmanan e cols (29) à abrangência de Maxon e cols (36). Um motivo para isto foi não mencionarem os primeiros (29), itens específicos a serem eliminados, nos diferentes grupos de alimentos, com riscos de comprometer o resultado da dieta. Além disso, ambas podem deixar dúvidas, a serem sanadas, no caso de Maxon e cols (36), por dietistas, nem sempre disponíveis nos consultórios médicos. Embora enfatizem tratar-se de dieta balanceada, não mencionam as carências associadas, sobretudo de cálcio e vitamina $A$, contidos nos excluídos lacticínios. Evitou-se a restrição calórica ado- 
tada no regime de Maxon e cols (36). O motivo fundamental para complementar a dieta de Lakshmanan (29), foi a falta de menção explícita aos alimentos a screm ingeridos, ao invés de apenas citar os omitidos. Para atender a estas motivações, expôs-se inicialmente, uma reprodução da dieta de Lakshmanan e cols (29), ampliada por proscrições e recomendações adicionais (tabela 1). A seguir, transcreveram-se as 6 listas de Maxon e cols(36), cada uma contendo os alimentos

Tabela 1 - Dieta com restrição de iodo: Itens Proibidos e Recomendações Adicionais* (Modificada de Lakshmanan e cols (6)).

\section{ITENS PROIBIDOS}

1. Sal iodado ou marinho, e em qualquer forma como sal temperado.

2. Lacticínios: leite, sorvete, queijo**, logurte, etc.

3. Gema de ovo.***

4. Frutos do mar: peixe de mar, moluscos, crustáceos, algas ou cinzas de algas.

5. Alimentos que contêm os aditivos: carragem, agaragar, algin, alginatos.

6. Alimentos preservados em sal, salmora ou defumados: carnes enlatadas, secas, salgadas ou em conserva por salgamento ou defumação, tais como toucinho salgado defumado, salsichas, presunto, carne conservada em salmora, salmão defumado, chucrute, vegetais enlatados, com sal, seus sucos e sopas, ketchup, molho de chili, azeitonas, picles, condimentos picantes fortes, caldo de carne em tabletes, ervilhas e feijōes e brócolis enlatados, bolachas salgadas.

7. Pães feitos com condicionadores de massa iodados.

8. Alimentos e medicamentos contendo corante vermetho Red $n^{2} 3$ ou vermelho $n^{\circ} 3$, tais como cereais, doces ou vitaminas vermelhos ou cor-de-rosa.

9. Chocolate

10. Melaço ou melado.

11. Produtos de soja (molho de soja, leite de soja)

12. Café e chá instantâneos ou solúveis.

\section{RECOMENDAÇÕES ADICIONAIS}

1. Evite alimentos de restaurantes ou lancherias. É impossivel determinar os que usam sal iodado, corantes, produtos de soja, etc.

2. Evite alimentos não caseiros, de origem desconhecida.

3. Verifique os ingredientes, nos rótulos, para evitar alimentos ou substâncias proibidas.

4. Alimentos que contêm pequenas quantidades de leite ou ovos (tortas, pães, etc.) podem ser usados.

5. Consulte seu médico, antes de suspender medicamentos de cor vermelha ou que contenham lodo, e a propósito de eventual prescrição de medicamentos contendo cálcio e vitamina A, deficitários na presente dieta.

* Utilizar água desiodada, em locais em que o iodo é usado na sua purificação (46). O ar é fonte de iodo (46). Evite-se sua sublimação no ambiente e qualquer contato com ele.

* Queljo natural não industrial sem aditivos, tais como soro de leite (46), é pobre em iodo (48) e pode ser ingerido.

** A clara contém pouco iodo $(61,62)$. Apenas a gema deve ser excluída. permitidos e as respectivas omissões (tabela 2 ). O paciente pode atentar apenas para os dados da tabela 1 , ingerindo o que não foi excluído. Certamente se beneficiará, conhecendo, pela tabela 2 , os alimentos permitidos para compor o seu cardápio. Com base em dados da literatura, o autor inseriu a clara de ovo $(61,62)$ e o queijo natural $(48)$, como alimentos pobres em iodo. Visou-se a tornar a dicta auto-explicativa. Por medida de segurança, incluiu-se a recomendação de uso de suplementos de cálcio e vitamina $A$, a critério do médico.

\section{Eficácia das DRI}

Será apreciada no que tange a: 1. Redução do pool corporal de ${ }^{27} \mathrm{I} ; 2$. Rastreamento; 3 . Doses ablativa e terapêutica

\section{Eficácia na Reduçāo do Pool Corporal de 127|}

Pode-se avaliá-la pela queda do iodo urinário, que também serve para confirmar a adesão ao regime. Hamburger (28) e Hamburger e Desai (31), não o mediram, mas Goslings (35), possivelmente com a dieta de Hamburguer, observou em quatro dias, queda da iodúria média de 121,6 para 30ug ao dia, apenas com dieta, e de 157,2 para 30,7 ug ao dia, com a combinação de dieta e ácido etacrínico.

Maxon e cols (36) observaram 40 pacientes com carcinoma diferenciado de tircóide, todos hipotireóideos, devido a prévia tireoidectomia e, em alguns, dose ablativa. Os 21 pacientes mantidos em dieta usual, excretaram na urina, em média, 346,9ug de iodo por grama de creatinina por dia, enquanto 19 submetidos a uma semana de DRI, excretaram em média 42,8ug de iodo/grama de creatinina por dia. Eles consideram suficientes 7 dias de dieta.

Lakshmanan e cols (29), em 5 pacientes atireóticos, determinaram iodo por grama de creatinina, em amostras ocasionais de urina, constatando média de $209 \mathrm{ug} / \mathrm{g}$ creatinina na fase inicial, sob dieta usual, e de 49 ug sob DRI. O curioso é que a queda se deu de forma brusca, logo após o início da dieta, em pelo menos 3 dos 5 pacientes. Fizeram duas constatações interessantes: aumentos instantâneos de 3 a 5 vezes, na iodúria, por indiscriçōes alimentares, indicando a necessidade de rígida adesão à dieta, e não interferência do uso de trioiodotironina, na excreção urinária de iodo, sob DRI. Diante da queda alcançada na iodúria, similar à de Maxon (36), com a qual, como se verá, obteve-se mais que duplicação na dose de radiação sobre restos de tireóide, enfatizam os autores a simplicidade e facilidade de sua DRI (29). Concluem que, embora 7 dias possam bastar (36), duas semanas sob 
Tabela 2 - Dieta com restrição de iodo: Listas de Alimentos Permitidos e Respectivas Omissões (Modificada de Maxon e cols (17)).

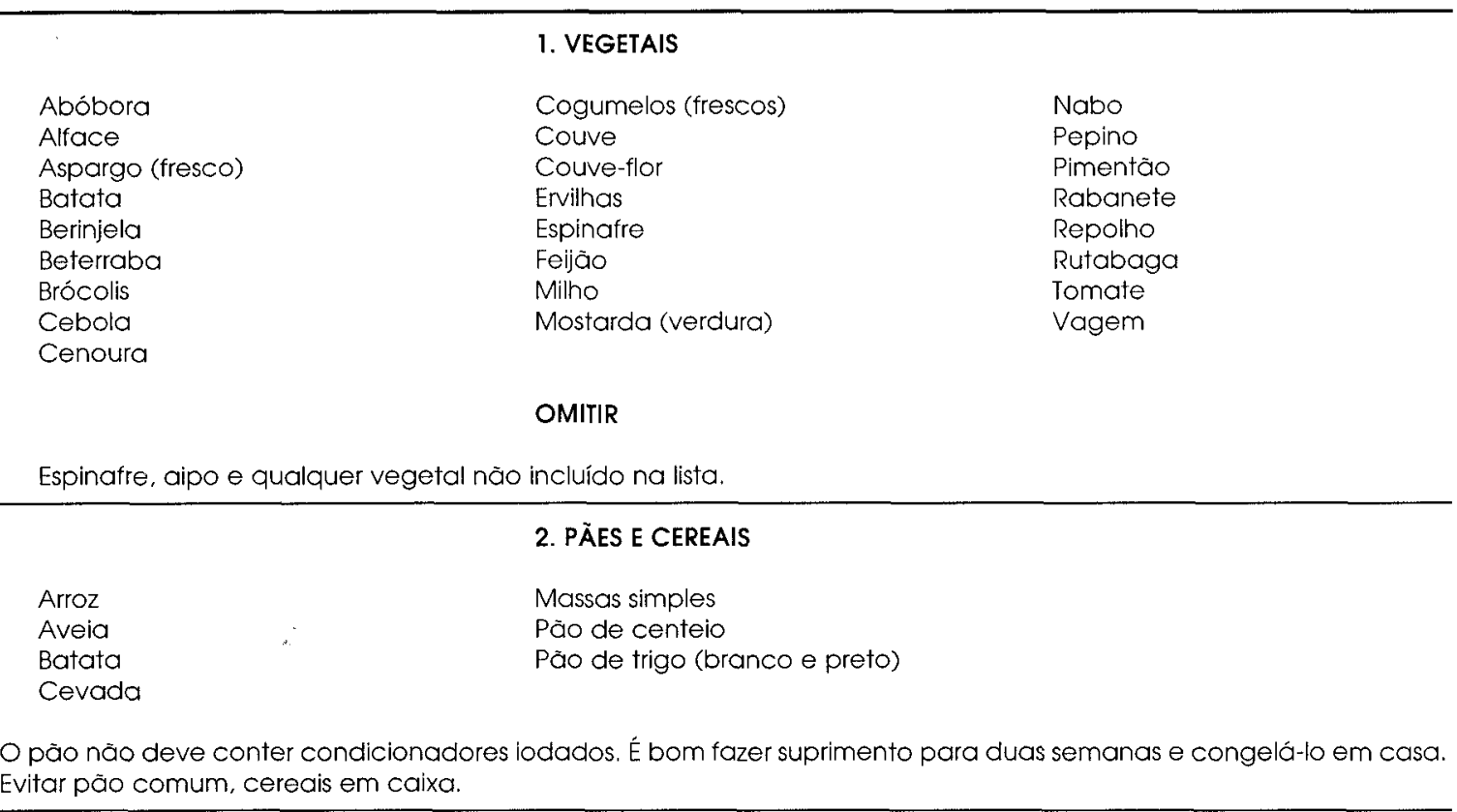

\section{FRUTAS FRESCAS}

$\begin{array}{lll}\text { Abacate } & \text { Limão (suco) } & \text { Nectarina } \\ \text { Ameixa } & \text { Maçã e seu suco } & \text { Pêssego } \\ \text { Figo } & \text { Manga } & \text { Tangerina (bergamota) } \\ \text { Laranja e seu suco } & \text { Melão } & \text { Uva e seu suco }\end{array}$

\section{OMITIR}

Banana, frutas secas, purê de maçã enlatado, pêssego enlatado e outras frutas não incluídas na lista.

\section{CARNES FRESCAS E PROTÉICOS}

Peixe de água doce: carpa, dourado, piava, traíra

Clara de ovo

Manteiga (pasta) de amendoim sem sal*

Boi

Porco

Vitela

\section{OMITIR}

Figado, frango, manteiga (pasta) de amendoim com sal, e outros não incluídos na lista.

\section{LACTICINNIOS E GORDURAS}

Caldo ou molho de carne caseiro

Gordura para bolos, pastéis, massas, folhados

Queijo natural não industrial, sem soro de leite e aditivos

Temperos para salada à base de óleo e vinagre

\section{OMITIR}

Banha e temperos comerciais para salada

Açúcar

\section{DIVERSOS}

Café passado

Gelatina com fruta ou suco permitido

Sal não iodado

Balas de goma (não vermelhas)

Chá por infusāo das folhas

Marchmelo

"Duas cotheres de sopa, de pasta de amendoim, correspondem a $33 \mathrm{~g}$ de carne. 
dicta podem ser mais eficazes, até completarem-se os testes ou eventual dose terapêutica com ${ }^{131} \mathrm{I}$.

Comprovou-se assim repetidamente a eficácia das DRI isoladas, $\mathrm{cm}$ promover expoliação de iodo corporal. Na verdade, é clássica a recomendação de DRI informal, de omitir o paciente, frutos do mar e iodo exógeno (59), embora nunca se tenha provado a eficácia desta conduta (29), que não tem o poder convincente de uma dieta bem definida, por escrito. Além disso, pelo menos nos EUA, a contribuição dos pescados, à ingestão global de iodo, ć inferior à de outros alimentos (45). Lembre-se que pecadilhos dietéticos provocam elevações súbitas da iodúria (29), através da qual se comprova, não só eficácia do regime, como a adesão do paciente. Recomenda-se que a excreção seja $\mathrm{em}$ torno de (ou inferior a) $50 \mathrm{ug} / \mathrm{g}$ creatinina/dia (36) ou $50 \mathrm{ug} / \mathrm{g}$ de creatinina (29). Outros requerem que seja menor que $100 \mathrm{ug} / \mathrm{g}$ de creatinina (63). Este é um ponto central, que será abordado em "Problema da Adoção das DRI: 3. No Brasil."

\section{Eficácia do Rastreamento}

Este dado pode ser apenas inferido, pois, excetuados os específicos sobre DRI, não se conhecem relatos comparativos. São muito poucos os exemplos de investigação clínica que mencionam DRI nos EUA $(23,28,29,31,32,34-37,64-66)$. A maior parte das publicações em que é usada, apenas registram o seu emprego, ora nāo informando a procedência, ora referindo as descritas em "As DRI existentes". Em nenhuma dos trabalhos, comenta-se o efeito da dieta nos resultados apontados, nem fazem-se comparaçōes com trabalhos em que a DRI não é utilizada. Os elementos de que dispomos são os de Hamburger, Goslings, Maruca, Maxon e Lakshmanan e respectivos colaboradores. Hamburger e Desai (31), observaram aumento de 2 a 3 vezes na captação de ${ }^{131}$ I em 5 de 7 pacientes com tumor residual. Os 2 que não mostraram melhoria, tinham captação de $2 \%$, prévia à expoliação de iodo com DRI e manitol. Em dois dos cinco responsivos, o acréscimo de captação permitiu detectar presumíveis metástases ganglionáres, enquanto nos demais três, evidenciou-se tumor residual. Em trabalho posterior, Hamburger (28) empregou DRI associada aos diuréticos manitol ( 9 pacientes) ou ácido ctacrínico ( 16 pacientes), observando aumento de 2 a 3 vezes na captação de ${ }^{131} \mathrm{I}$, em 7 dos primeiros e 9 dos últimos; entre estes, 3 mostraram incremento menor e 4, mínimo a nulo. Em 6 pacientes, demonstrou-se que o ${ }^{131}$ I captado após ácido etacrínico é retido por pelo menos 96 horas. Em ambos as trabalhos, conclui-se que, assim como já presumiram Barakat e Ingbar (32), o aumento da captação é independente de aumento secreção do TSH, já elevada ao máximo, portanto, não resultando em aumentada liberação do ${ }^{131} \mathrm{I}$. Hamburger (28) não teceu comentários sobre o rastreamento, senão sobre o efeito terapêutico, que será abordado adiante no item 3 .

Goslings (35) demonstrou aumento médio em um fator de 1,79, na captação de $131 \mathrm{I}$, sob DRI, o que tem relevância na detecção de tecidos iodocaptantes. Mas observou também incremento na meia-vida efetiva do 131 I, nas lesões, o que tem vantagem terapêutica, a ser analisada no item 3. Maruca e cols (34), utilizando a DRI de Hamburger (28), associada a hidroclorotiazida ou furosemida, demonstraram aumento médio de $146 \%$ na captação c retenção no tecido tumoral, portanto favorável à deteç̧ão de tecido funcionante. Outras medidas efetuadas no trabalho, relevantes para o tratamento, serão abordadas $\mathrm{cm} 3$.

Maxon e cols (36) apresentaram os resultados da dose de radiação, em rads por $100 \mathrm{mCi}$ de ${ }^{131} \mathrm{I}$ administrados, não informando as cifras de captação. Entretanto, a elevação desta, sob DRI, fica implícita, pelo mcnos em restos de tireóide, favorável a sua melhor demonstração cintilográfica. Os dados mais importantes deste trabalho dizem respeito ao item 3. abaixo.

Lakshmanan e cols (29) atêm-sc a informar a redução na iodúria para cerca de 50 ug ao dia, com a DRI simplificada que propõem, favorecendo o aumento da captação de ${ }^{131}$ I relatado na literatura, em decorrência da expoliação de iodo, propício ao rastremanto, sem que tivesse isto sido testado por eles. É a dieta que usam no manuseio dos pacientes de sua instituição, citada em suas publicações $(23,29,57)$.

\section{Eficácia de Doses Ablativa e Terapêtica}

Interessa definir em que grau o uso de DRI aumenta ou não, esta eficácia. Da mesma forma que no item 2 ., há muito pouco publicado a respeito. Como já comentado, nas publicações em que a DRI é adotada, não existe informação sobre a eficácia, e muito menos, dados comparativos. Voltamos a analisar os trabalhos apresentados na seção "As DRI Existentes".

Hamburger (28) relata o seguimento de 13 dos 25 pacientes que receberam dose terapêutica, após aumento exitoso da captação com sua dieta e diuréticos. Em 12, desapareceu a atividade iodocaptante detectada antes do tratamento, em áreas de suspeita do tumor. No restante, que apresentara captação em linfonodos cervicais, em lesão pulmonar, assim como cm todo o lobo esquerdo remanescente, a primeira dose terapêtutica destruiu o lobo, requerendo nova dose que suprimiu a função das áreas metastáticas. A eficácia de seu 
regime (28) resultaria do aumento de captação não acompanhar-se de elevação do TSH e de demorar-se o 131 I por pelo menos 96 horas, nas lesões. Comenta ainda que a captação do tumor deve ser máxima, admitindo regime expoliativo, ainda quando a captação sobre o tumor for suficiente para o tratamento com ${ }^{131}$ I, para permitir doses menores do radioisótopo. Veremos, em "Problema da Adoção das DRI: 1. Nos EUA", que desta opinião participa Mazzaferri (67). Goslings (35), embora contradizendo o papel potenciador do ácido etacrínico sobre a depleção de iodo, defendido por Hamburger (28), chega a resultado similar ao deste, ao demonstrar incremento por um fator médio de 1,19 na meia-vida efetiva do ${ }^{131}$ I captado pelo tumor, após 4 dias da DRI. Como se viu no item 2., ele comprovou aumento na captação por um fator médio de 1,79 . O produto $1,19 \times 1,79=2,13$ representa o fator médio de aumento na dose tumoral, em decorrência da DRI, o que melhora a eficiência, permitindo reduzir a dose total de $131 \mathrm{I}$ administrada (35).

Maruca e cols (34), em 3 pacientes tireoidectomizados, com metástases residuais funcionantes, demonstraram que, a despeito de um aumento médio de $174 \%$ na captação em tecido tumoral, similar aos de Goslings (35) e Hamburger (28), tiveram aumento de $68 \%$ na radiação corporal total por $150 \mathrm{mCi}$ de ${ }^{131} \mathrm{I}$ administrados, em decorrência de DRI associada a diuréticos. Com isto, decretaram a abolição do regime de Hamburger $(28,31)$. Entretanto, fica o registro do aumento de captação, que é vantajoso, na DRI isolada. Não há avaliação do efeito da dieta sobre os resultados terapêuticos do 131I, neste trabalho (34).

Maxon e cols (36) apresentaram os seus resultados comparativos de dose de radiação em rads por $100 \mathrm{mCi}$ administrados de $131 \mathrm{I}$, em 19 pacientes isentos de tratamento prévio com ${ }^{131} \mathrm{I}, 8$ sob dieta usual (iodo urinário maior que $100 \mathrm{ug} / 24 \mathrm{~h}$ ), sendo $4 \mathrm{com}$ metástases e 4 com restos de tireóide, e 11 sob DRI (iodo urinário menor que $100 \mathrm{ug} / 24$ horas), sendo 6 com metástases e 5 com restos de tireóide. Não observaram diferença na dose de radiação, pela DRI, nos casos com metástases, indicando não haver ganho terapêutico, nesta categoria, talvez por menor tempo de retenção do ${ }^{131}$ I nestas lesões. Em pacientes apresentando apenas restos de tireóide, houve aumento de 2,3 vezes em rads, por $100 \mathrm{mCi}$ de 131 I administrados. Embora o resultado seja sugestivo, era pequeno o número de casos e as diferenças não foram significativas. Concluem que a DRI pode ser seguro e potencialmente útil adjunto no tratamento ablativo com ${ }^{131} \mathrm{I}(36)$.
Como se vê, não resta dúvida que as DRI com ou sem diuréticos, ao aumentar a captação de ${ }^{131} \mathrm{I}$, favorecem a demonstração de restos de tireóide e de tumor. É possível que sejam úteis no que respeita a dose ablativa, embora não se tenha observado efeito em dose terapêtica. Inexistem trabalhos que provem o impacto sobre os índices de cura, recidiva e sobrevivência. Como isto talvez nunca venha a ser feito $(5,9)$, é lícito concluir que tudo o que permita maior eficácia terapêutica e análise mais precisa, quanto à existência de restos de tireóide ou tumor, deva ser tentado. Cabe aqui o axioma: "A DRI pode às vezes não ser benéfica, a contaminação é sempre maléfica", no manuseio do câncer diferenciado de tireóide com ${ }^{131} \mathrm{I}$.

\section{PROBLEMA DA ADOÇĀO DAS DRI}

É evidente estar ligado à eficácia das DRI. Viu-se que, embora incerta a eficácia quanto a dose terapêutica (36), sĩo as DRI eficientes em reduzir o pool corporal de ${ }^{127} \mathrm{I}(29,35,36)$ e favorecer rastreamento corporal $(28,31,34,35)$, provavelmente eficazes, no que tange a dose ablativa (36). Estes dados permitiriam esperar que se tornassem rotina. Todavia, não é o que se verifica na literatura, apesar de ter-se demonstrado redução na medida da atividade iodocaptante da tireóide (3941,51-53), em decorrência do aumento do conteúdo em iodo, na dieta dos americanos (38-41), provocado pelo elevado teor do elemento, em algumas fontes nutritivas (41-50). De um valor usual de 160 a 250 ug ao dia, elevou-se a quota de iodo a cerca de 240 a 740 ug ao dia, como se constatou em fins da década de $60(39,40)$. Levando em conta ter-se demonstrado que a adição diária de $300 \mathrm{ug}$ de iodo reduziria parcialmente, enquanto 1000 ug a 2000 ug suprimiriam, em três semanas, a captação tireóidea de ${ }^{131} \mathrm{I}(68)$, a cifra de 1000 ug sendo atingida com o mero acréscimo de 4 fatias ao dia, de pão rico em iodo (41), fica óbvio o transtorno potencial sobre o manuseio de câncer de tireóide com ${ }^{131}$ I (29). Estas constatações motivaram a proposta, por Maxon e cols (36), de DRI palatável, para preencher lacuna existente na literatura, e também a que se seguiu, de Lakshmanan e cols (29), mais simples e fácial de seguir, ambas referidas em publicações posteriores $(23,24,57,67)$. Mau grado isto, o tema é pouco abordado. Não consta, no Index Medicus, descritor referente a "Dieta com Restrição de Iodo", sendo escassas as publicações específicas, limitadas às descritas na seção "As DRI Existentes", em revisão na Medline que compreendeu o período de dezembro de 1976 a fevereiro de 1998, e que permitiu colher dados às vezes intrigantes, senão surpreendentes. 
$\mathrm{Na}$ exposição que se segue, enfatizam-se relatos mais recentes, com relevância para a conduta atual. Analisa-se a adoção 1. Nos EUA; 2. Na Europa e alguns países; 3 . No Brasil.

\section{Nos EUA}

Se a motivação primordial, para uso de DRI de rotina $(29,36)$, foi a elevada quota de iodo, na dieta dos americanos (38-4l), ao analisar sua adoção, importa conhecer as fontes do aporte excessivo, e sua prevalência no presente. Quanto às fontes, verifica-se que poucos foram os itens apontados (41-50). Destacamse os lacticínios, os pães e produtos de padaria, a eritrosina ou vermelho $n^{\mathrm{O}} 3$, produtos de grãos e cereais, os ovos (analisados pelos autores dentro do grupo de carne, pescados e aves), açucares e adjuntos, e medicamentos. Por muito tempo, os lacticínios predominaram (47). O conteúdo aumentado do iodo no leite decorreu do uso de sal e produtos minerais iodados na ração animal, para combater a deficiência de iodo nos EUA (47). Além disso, contribuíram produtos veterinários e sanitários, e desinfetantes iodados usados nas fazendas de ordenha $(46,49)$. As glândulas mamárias concentram e secretan iodo para o leite (46). Na fabricação do queijo, a maior parte segregase no sôro do leite (46), muito utilizado na industria alimentar, sendo acrescido a leites, queijos e derivados industriais (48), embora o queijo natural seja pobre em iodo (48). A indústria leiteira tratou de reduzir o conteúdo em iodo da ração e de utilizar agentes de limpeza e esterilizantes não iodados, provocando redução da ingestão de iodo entre 1974 e $1981 / 82$ (49). Em 1965, verificou-se em Bethesda, MD, conter o pão grandes quantidades de iodo, derivado de condicionadores de massa iodados (42), pelo processo de panificação da mistura contínua $(45-47,49)$, chegando-se a detectar $150(39,42)$ até 268 ug $(41)$ por fatia. O processo extendeu-se, a ponto de, em 1969, a metade do pão branco de forma ser fabricado segundo ele, nos EUA (39). Entretanto, à época, já se tentava introduzir novo agente (39), sendo depois os iodados substituídos por condicionadores à base de bromatos (48). Como isso não aboliu de todo o conteúdo em iodo, é possível que provenha de fontes alternativas (47). Uma fração provém da própria farinha, de fermento, leite, e outros componentes (39), assim como de sal iodado (45). Não se deve esquecer que outros produtos de pães e cereais podem conter leite (45), assim como o corante eritrosina (vermelho $n^{\circ} 3$ ) $(46,47,49)$. A eritrosina, tetraiodofluoresceína, é um corante com $57,7 \%$ de iodo, denominado FD\&C Red № 3, pelo FDA que, tendo em 1976 suspenso o uso dos de números 2 e 4 , resultou em quase o dobro de emprego do número 3 (46). A disponibilidade de seu iodo é limitada, mas pode aumentar muito quando submetido ao processamento industrial dos alimentos (48). Embora alguns duvidem de sua importância na dieta, senão quando poucos alimentos são selecionados (47), outros consideram-no significativa fração da ingestão diária de iodo (44), largamente usado cm cosméticos, alimentos e drogas (50). Entre os alimentos que o contêm, destacam-se cereais integrais corados (44), açúcares e adjuntos $(46,48,49)$, podendo estar contido de forma sutil em medicamentos (46). Talvez a esse respeito, seja indiscutível o valor de DRI prescrita, que faça menção definida à necessidade de excluírem-se medicamentos ou alimentos industriais, em que sua presença esteja expressa no rótulo, a despeito de que, nos EUA, a maioria senão todas as industrias de fabrico de cereais tenham descontinuado o seu emprego (48). Os produtos de grãos e cercais industrializados eram freqüentemente corados com eritrosina (46), como relata-se acima, mas é corrente a adição de soro de leite, algas, temperos (46). Os últimos podem conter algas e sal iodado. Os ovos foram referidos como importantes fontes de iodo, sem alusão à sua origem, podendo contê-lo em quantidades superiores a $\mathrm{lug} / \mathrm{g}(45,47,48)$. As amplas faixas de conteúdo mínimo/máximo denotam influência de fatores exógenos. Pode admitir-se que decorram de rações contendo produtos iodados. Obtêm-se ovos muito enriquecidos, pelo acréscimo de alga à ração da galinha (69). Lembre-se que a maior parte do iodo encontrase na gema. A clara contém cerca de 3ug/lo0g $(61,62)$,sendo admissível em DRI. Açúcares e adjuntos, incluindo balas, doces e sorvetes, podem conter iodo proveniente de eritrosina, leite e sal $(46,48,49)$. Medicamentos podem conter sais de iodo, sobretudo iodeto, além de eritrosina, como corante das formas líquidas e das cápsulas de drogas (46).

No que concerne à prevalência atual, relembre-se que, em relato de 1970 , Oddie e cols mapearam a quota de iodo alimentar, verificando variar notavelmente, de 238 a 307, em algumas, até 500 a 738 ug ao dia, em outras regiões dos EUA (40). Com dados do Total Diet Study, coletados entre 1974 e 1981/82, Allegrini e cols (47) não registraram diferenças significativas, no conteúdo de iodo de alimentos (exceção feita de lactantes), entre as quatro regiões geográficas (nordeste, sul, norte central e oeste), a despeito da queda na sua ingestão, no período (49). Todavia, os dados mais recentes, do mesmo estudo, indicam que, não obstante aparente declínio, no período 1982 1991, as diferenças não são significativas $(70,71)$, com 
ingestão muito superior aos 150 ug diários recomendados para adolescentes e adultos (72), devido ao alto conteúdo, em alguns alimentos (7l). Destacam-se produtos de grăos, leite e queijo, carnes (incluindo peixe) e pratos mistos e sopas (71). São achados relevantes por dois motivos : primeiro, por indicar a persistência de elevado teor de iodo na dieta, nos EUA, e segundo, por demonstrar a praticabilidade de reduzi-lo, pela exclusão de alguns itens alimentares. Ambos deveriam tornar imprescindível a prescrição de DRI, no manuseio do câncer de tireóide, com ${ }^{131} \mathrm{I}$, nos EUA, ao passo que, na maioria das publicações, o uso das DRI não é incluído em "Materias e Métodos", embora tenha Beierwaltes proposto considerar-se seriamente seu emprego, antes do tratamento com radioiodo (2).

No período de observação que vai até 1982 , excetuados os trabalhos específicos $(28,31,32,35)$, c a proposição acima citada de Bcierwaltes (2), não encontrou-se relato recomendando o uso rotineiro de DRI, quer em revisão (27) quer cm sérics pequenas (73), ou grandes (74-77) de pacientes. Como exceção, Leeper e Shimaoka (12) indicam-na em pacientes selecionados e nos que não demonstram captação de ${ }^{131}$ I pelo tumor, portanto não rotineiramente. É digno de nota, não haver adesão a DRI, nas publicações ulteriores de Beierwaltes, inclusive quando discute a eficácia do decálogo de conduta de seu grupo (78). Em verdade, é tácito o reconhecimento de que o paciente deva abster-sc de iodo exógeno e pescados, antes de exames $\mathrm{e} / \mathrm{ou}$ tratamentos com ${ }^{131} \mathrm{I}$, devendo-se presumir que, nas clínicas de manuseio de pacientes com câncer de tireóide, interdição a estes itens seja rotina. Aliás, Edmonds (59), em Londres, alegando dificuldades práticas e pequena melhora obtida com DRI ou diuréticos, na escusa à adoção destas medidas, sugere cvitar iodo exógeno c abstenção de peixe por 4 sumanas. É possível que a falta de impacto, apontada por Edmonds, resulte de que a DRI só deva atuar em pessoas que ingiram quantias elevadas de iodo-127, conjectura făcil de clucidar, através de iodúria de rotina, prévia a rastreamento/tratamento com ${ }^{131}$ I (ver item 3. adiante).

Entre publicações amcricanas de 1985 a 1998, com período de observação que se extende após 1982, não há alusão a DRI, em grandes séries (79), provindas de clínicas importantes (80-82). Tampouco há menção a DRI, em trabalho sobre séric menor em grande hospital (83). Isto, além de ser surpreendente, deve suscitar dúvidas quanto aos resultados observados, cnvolvendo o uso de 131. Exemplar é o "stunning" (aturdimento), queda de atividade iodocaptante do tumor, após rastreamento com doses de ${ }^{131} \mathrm{I}$ superiores a $2 \mathrm{mCi}$
$(24,84)$. Embora pareça indiscutível, por ter prevalência proporcional à dose de ${ }^{131} \mathrm{I}$ (85), resta sempre a possibilidade de contaminação, precedendo a dose terapêutica, pois não é fênômeno constante. O mesmo se aplica a pacientes com rastrcamento negativo associado a tircoglobulina detectável (86) ou a tumor perceptível por outros recursos.

Quanto às revisões em livros texto, destaque-se a omissão de DRI, por membros de grande clínica (87), confirmando outras publicações da mesma origem $(76,77)$, atitude mantida em trabalho de revisão sobre câncer folicular de tircóide (88), surprecndente, face à queda da atividade iodocaptante da tireóide, lá relatada (53). A DRI é omitida cm texto (13), contradizendo publicação anterior, $\mathrm{cm}$ que dicta pobre em iodo informal é recomendada (89). Esta omissão se opõe, por igual, à conduta do grupo de que aquelc autor participa, em que DRI não é prescrita, embora com a cautela de que sejam medidos iodo c creatinina urinários, antes de cada rastrcamento (15).

Em contraste com estes dados, é surpreendente que, dos membros da American Thyroid Assaciation, inquiridos sobre o manuseio do carcinoma papilar bem diferenciado, $55,3 \%$ recomendariam DRI, com adesão à dieta por uma (26\%) a duas (39\%) semanas, no preparo para dose ablativa, e $33 \%$, no preparo para rastreamento periódico, no seguimento após tratamento inicial, em paciente de menor risco, aumentando, até $63 \%$, no caso de maior risco (metástases pulmonares) (90). Como se verifica, a maioria, quando indagada, confirma o uso, o que reforça a conjectura de que é maior o número dos que usam, do que aqueles que o informam, nas publicações, por ser considerada uma conduta tácita, a recomendação de omitirem-se iodados exógenos e alimentos ricos em iodo.

A literatura vem mostrando uma reversão desta conduta, a partir de meados da década de 80. Mazzaferri, já em 1986, adotava DRI de rotina (58), bascada nos dados de Kidd e cols (45), por uma semana antes do rastreamento, mantendo-a por mais uma semana após dose terapêutica. Manteve a conduta em 1996, agora (67) bascada na dieta do grupo de Robbins $(29,57)$, nas duas semanas que precedem rastreamento/tratamento com ${ }^{131}$ I. Significativa é a transição de livro texto tradicional, entre 1985, onde nào se menciona (91), e 1992, em que a DRI é rotina, uma semana antes do rastreamento (92). Além disso, ć proposta como rotina em outros livros texto $(7,93)$, como preparo para rastreamento, assim como em revisões de literatura $(10,24,57,94,95)$, para rastrcamento/dose terapêutica. 
Quanto a trabalhos de investigação clínica, exceção feita dos referidos em "As DRI Existentes" $(28,29,31,32,34-36)$, poucos são os que empregam DRI de rotina, em geral adotando a do grupo $(23,37,64,65)$, sendo exceção o uso em relato de caso (66), assim como o cuidado em excluir pacientes com exposição recente a iodo (82).

Vê-se que, a despeito da crescente adoção, é ainda predominante a não adoção das DRI. Não se trata exatamente de repulsa, pois na maioria das publicações, o tema nem sequer é discutido, conduta que entra em choque com postura oposta que abordaremos no item 3. adiante, e contraria a ênfase de que o pool de iodo corporal deveria ser tão baixo. quanto possível, segundo Mazzaferri (67).

\section{Na Europa e Outros Países}

Prevalece ainda a não adoção das DRI. Há na Europa uma forte motivação neste sentido, pois, excetuados os países escandinavos, Suíça e Áustria, a maioria dos países europeus, ou ao menos áreas deles, ainda estavam em 1988, deficitários em iodo, especialmente os do sul. Em 1992, a deficiência estava controlada apenas em 5 países: Áustria, Finlândia, Noruega, Suécia e Suíça (60). É emblemático, em comparação com idêntico levantamento nos EUA (90), não haver-se incluído a utilização de DRI, em questionário sobre manuseio do câncer diferenciado de tireóide, na Europa, embora participassem correspondentes de todos os continentes (96). A DRI não foi utilizada em séries menores (97) c grandes (98-100), na Itália, em séries menores $(101,102)$ e grandes (103-105), na França, onde é característica a conduta omissa de grande grupo $(9,86,104,105)$. Não é citada em trabalho de grupo austríaco (106). O mesmo se verifica em grande série alemã (107). É também alemão grupo de investigadores quc, não recomendando DRI (108, 109), esclarecem ser baixa a suplementação de iodo no país, adotando a conduta didática de demonstrar menor excreção urinária média de iodo, nos pacientes, do que em população controle sem tireopatia (108). A não adoção é justificável em série moderada na Bélgica (110), onde ć dos mais acentuados o déficit de iodo na alimentação (60), mas injustificável em grupo inglês (111), diante do aumento descontrolado na ingestão de iodo, no Reino Unido, similar ao descrito nos EUA (112).

Afora a Europa, registre-se a não adoção, em série grande em Israel $(63)$ e séries moderadas no Canadá (113,114), onde, em sumário de conferência de consenso, discutiu-se dose ablativa, sem abordar o tema da DRI (115). É lamentável que se omita, em série pequena (116) e séric grande (117) no Japão, c outra na Corea do Sul ( 118 ), nos quais é, em algumas comunidades, elevada a ingestão de iodo (119). Deve-se condenar a recomendação de Kim e cols (118), de aumentar a dose ablativa, quando menos lesivo e mais eficaz seria prescrever DRI, tendo em vista a imediata queda que se observa na iodúria (29). Não se justifica omitir DRI, nestas regiões.

São escassas as publicações em que se adota DRI, surpreendentes, em países da Europa com baixa ingestão de iodo (60), como Itália (120) e Bélgica (121), não tanto em Taiwan (122), onde é alta a ingestão de derivados de algas.

Como se verifica, são ainda minoria, os autores que tentan reduzir ao mínimo a interferência da contaminação com ${ }^{127} \mathrm{I}$, na captação do ${ }^{131} \mathrm{I}$ para rastreamento/tratamento de câncer diferenciado de tireóide, embora seja digna de nota, a evolução dos livros texto, em prol da DRI.

\section{No Brasil}

No conhecimento do autor, não existe trabalho nacional sobre o tema, nem referência a uso de rotina de DRI, no manuscio do câncer diferenciado de tircóide com 131I (LILACS/CD-ROM, de 1982 a 1997). Indaga-se, no estado atual de informação, se o uso de DRI é justificável ou imperativo no Brasil. Os precisos dados, sobre a ingestão de iodo pelos americanos, levaram, na década de 80 , à criação de DRI própria $(29,36)$. Será que estes dados coincidem com os aqui prevalentes?

Carece, no Brasil, levantamento sobre o teor em iodo nos alimentos, muito mais em relação a cada uma das fontes de aporte excessivo, analisadas acima, no item "l. Nos EUA", e sobretudo no que tange aos fatores que resultam na elcvação do seu conteúdo, em alimentos como o leite, o pão, cereais, ovos e açúcares e adjuntos. Ignora-se a prevalência de uso da eritrosina e até do sal iodado. É lícito esperar-se que breve tenhamos, no Brasil, cstudo similar ao Total Diet Study $(46,47,49,70,71)$, que vem acompanhando o conteúdo mineral da dieta, nos EUA, há cerca de 30 anos. Se considerarmos os maiores responsáveis pelo alto conteúdo em iodo, na dieta dos americanos, seria pelo menos razoável, investigar o conteúdo em iodo do sal de cozinha, das rações animais, inclusive de aves, dos desinfetantes, produtos veterinários e sanitários empregados nas fazendas c indústria leiteira, dos condicionadores de massa da industria de panificação, assim como a prevalência do emprego de eritrosina (e.g. em balas, doces, sorvetes, medicamentos, produtos cereais) e de algas e derivados. Está o autor informado de que em São Paulo, empregam-se condicionadores de massa 
à base de bromato, na panificação. Em Porto Alegre, quiçá em todo Rio Grande do Sul, utiliza-se processo diferente, não incluindo condicionadores iodados. Em verdade, prevalece ainda condenável deficiência de iodo no país (123-126), que justificaria a não adoção da DRI, como o fizeram, na Alemanha, Grünwald e cols (108). Estes, entretanto, acautelaram-se quanto à existência de contaminação, através da medida do iodo urinário, que não é rotina em nosso meio.

Diante dos dados acima, indaga-se como proceder no Brasil, quanto às DRI: recusar? adotar? Até agora, salvo a recomendação de evitar pescados e iodo exógeno (nem sempre empregada), o uso é excepcional, limitado àqueles casos em que a baixa captação do ${ }^{131}$ I é atribuída a contaminação. Entretanto, até que se tenha noção precisa da quota de iodo, na dieta dos brasileiros, ou pelo menos se afaste a existência de conteúdo elevado do elemento em alguns alimentos, não é possível excluir a interferência de seu excesso na captação/eficácia do 131 I, 110 manuseio do câncer diferenciado de tireóide. Na ausência de conhecimento sobre o conteúdo alimentar de iodo, só restam duas alternativas: adotar DRI ou medir a iodúria, para assegurar a inexistência de contaminação. Até o presente momento, tem o autor, desde a publicação do trabalho de Pineda e cols (23), recomendado DRI por ele adatada, face à inacessibilidade a equipamentos apropriados aos métodos dispendiosos, sofisticados e cansativos existentes para a medida da iodúria. Esta é utilizada por autores que não recomendam DRI, mas asseguram-se contra a existência de contaminação $(15,108)$ ou prescrevem dieta, mas preferem confirmar sua eficácia $(29,35-37)$. Tratando-se de pacientes expostos a contaminação, por procedimentos cirúrgicos e radiológicos recentes, é a iodúria considerada de rotina (37). Um relato de março de 1998 pode revolucionar a conduta. Rendl e cols (127) apresentam teste rápido, acessível e não dispendioso, para medida semiquantitativa do iodeto urinário. Embora programado para trabalho de campo, no combate à deficiência do iodo, permite comprovar sua excessiva ingestão (127). Empregado antes do rastreamento/tratamento com ${ }^{131} \mathrm{I}$, poderá revelar se o paciente está habilitado ou reguer DRI prévia, simplificando a conduta, ao assegurar a inexistência de contaminação inculpável por baixa captação de ${ }^{131} \mathrm{I}$, como no fenômeno de "stunning", e na associação de rastreamento negativo com tireoglobulina detectável ou com tumor perceptível por outros recursos. Falta, contudo, estabelecer em que grau e freqüência, outros sais de iodo (e.g. iodato), não identificados no teste, podem prevalecer, em algumas fontes de contaminação.

\section{CONCLUSÕES}

A partir da demonstração de que a expoliação corporal de iodo aumenta a atividade iodocaptante do tumor, historiam-se as DRI, no contexto do uso do ${ }^{131} \mathrm{I}$, no tratamento do carcinoma diferenciado de tireóide, frente ao problema fundamental da captação do radioisótopo, essencial a seu efeito. Incluem-se desde as primitivas, associando diurético, às recentes, dispensando-o, igualmente eficazes, mais palatáveis e simples.

Analisam-se os mecanismos do aumento de captação por DRI: elevação na relação corporal de ${ }^{131}$ I/ 127 I e na captação do isótopo pelas células tircóideas, decorrentes da expoliação de iodo, e, quando associadas a diuréticos, queda na depuração renal de ${ }^{131} \mathrm{I}$, que origina aumento indescjável na radiação corporal.

Comenta-se o aumento na ingesta de iodo, no EUA, que resultou em redução na taxa da captação do ${ }^{131}$ I, e a conseqüiente transição do uso eventual da DRI, para o de rotina, no sentido de obter a máxima captação, reduzir a dose de ${ }^{131}$ I e, portanto, a radiação corporal.

Descrevem-se as DRI existentes, e a DRI do autor, uma fusăo adatada e modificada das mais recentes, de Maxon e cols (36), que enfatiza alimentos permitidos, e de Lakshmanan e cols (29), alimentos proibidos, de modo a torná-la completa e auto-explícita, dispensando a necessidade de dietistas, nem sempre disponíveis nas clínicas.

Comenta-se variar o tempo recomendado de dieta entre 7 dias (36) e 14 dias (29), antes de rastreamento ou dose ablativa/terapêtutica.

Analisa-se a eficácia das DRI, quanto à redução do pool corporal de ${ }^{127} \mathrm{I}$, ao rastreamento e às doses ablativa/terapêutica. A primeira fica evidente pela freqüente queda brusca e acentuada da iodúria, em pacientes com câncer diferenciado de tireóide, sob DRI isolada ou associada de diurético, considerando-se adequada a expoliação corporal de iodo, quando a iodúria não ultrapassa $50 \mathrm{ug} / \mathrm{dia}$ ou $50 \mathrm{ug} / \mathrm{g}$ de creatinina. Comenta-se que esta medida serve para avaliar a adesão ao regime, denunciando instantâneas indiscrições alimentares, motivo para exigir-se regime estrito. Como corolário, revela contaminação que imponha DRI, tornando-se fundamental na conduta adiante recomendada. No que respeita ao rastreamento, estudos evidenciaram, com DRI, aumento na captação de 131 I em restos de tireóide e tumor, em boa parte dos pacientes, favorecendo sua evidenciação, independente da secreção de TSH e persistente por, pelo menos 96 horas, acompanhando aumento da meia-vida efetiva do isótopo na lesões, dados propicios ao efeito terapêutico. 
Poucos são os estudos relativos à eficácia de doses ablativa $\mathrm{c}$ terapêtutica. Investigações que demonstraram aumento de captação e de dose de radiação tumoral, com DRI, não inclúram avaliação comparativa, excetuado o de Maxon e cols (36). Estes, em número pequeno de pacientes, não observaram influência de DRI na radiação $\mathrm{cm}$ dose terapêutica. Verificaram aumento de 2,3 vezes na radiação sobre restos de tireóide. Embora, as diferenças não fossem significativas, os dados são sugestivos da utilidade da DRI em dose ablativa.

Sumarizando a eficácia, não resta dúvida que as DRI favoreçam a expoliação de ${ }^{127} \mathrm{I} \mathrm{e}$ o rastreamento, é possível que sejam úteis quanto a dose ablativa, não se tendo demonstrado efeito em dose terapêutica. Contudo, são poucos os estudos realizados, sendo inexistentes os que enfoquem o impacto da DRI no prognóstico. Como é objetivo quiçá inatingivel, propõe o presente autor um axioma "A DRI pode não ser benéfica, mas a contaminação será sempre maléfica".

Analisando o problema da adesão às DRI, verificase, em revisão da literatura, a escassez de publicações concernentes e a raridade de adoção, em relatos de investigação clínica, apesar de que a elevada quota de iodo, na dieta, nos EUA, Reino Unido e algumas regiões da Ásia, tenham conduzido a queda importante na atividade iodocaptante da tireóide, que provocou a criação das mais recentes DRI. Para avaliar esta questão, revisaram-se as fontes não evidentes do aporte excessivo de iodo nos EUA. Destacaram-se, no passado, lacticínios, pães e produtos de padaria, produtos de grãos e cercais, ovos, açúcares e adjuntos, medicamentos e critrosina (vermelho $\mathrm{n}^{\circ} 3$, corante usado $\mathrm{cm}$ cereais, açucarados, medicamentos, etc.). Mantém-se ainda elevado, nos locais acima referidos, o teor alimentar de iodo, apontando-se hoje produtos de grãos, leite e queijo, carnes, e pratos mistos e sopas, nos EUA, o que torna simples a prescrição de DRI. Os fatores primordiais cifram-se ao uso de produtos iodados nas rações e no trato de animais, assim como na indústria de alimentos e de medicamentos, tanto nos EUA, como no Reino Unido, e ao uso de algas, na Ásia.

Em contraste com estes dados, alerta-se, após revisão de literatura americana, para a surpreendente raridade de alusão a DRI, senão em contados relatos, para casos excepcionais de baixa atividade iodocaptante pelo tumor, inexistindo $\mathrm{em}$ análises de grandes séries de pacientes, manuseados com ${ }^{131} \mathrm{I}$. As dúvidas, quanto aos resultados destes estudos, podem ser minoradas se se cogitar que DRI informal deva ser rotina, nestes centros, não registrados cm "Materiais e Métodos" dos relatos. Tanto, que vem se verificando incre- mento à recomendação de rotina, em livros texto e revisões de literatura. Destaque-se, por igual, o resultado de pesquisa revelando recomendarem DRI, no preparo para DOSE Ablativa, 55,3\% e Para rastreamento, até $63 \%$ (segundo o risco) dos membros da American Thyroid Association, reforçando a hipótese do autor, de predominar o número dos usuários, sobre o de informantes, nas publicações. Na Europa, destaca-se a raridade da DRI, apropriada à prevalente deficiência de iodo. Distingue-se conduta didática de grupo alemão (88), que utiliza iodúria, para excluir contaminação, a despeito da carência de iodo vigente. Entretanto, aponta-se a injustificável omissão da DRI, em trabalhos de grupo inglês e do Extremo Oriente, onde, em certas regióes, prevalece elevada quota alimentar de iodo. Condena-se a recomendação de grupo coreano, para aumentar-se a dose ablativa, face à elevada quota de iodo, ao invés de prescrever DRI.

Ao abordar a questão no Brasil, comenta-se a inexistência de DRI publicada, duvidando-se da sua necessidade, face à deficiência endêmica de iodo, ainda prevalente em certas regiōes do país, inclusive não montanhosas. Entretanto, diante do desconhecimento sobre o conteúdo nos alimentos e sobre a existência de excesso similar ao dos EUA, aponta-se à imperiosa necessidade de estudo similar ao Total Diet Study, que informe a situação vigente, pelo menos em relação aos itens lá implicados.

Conclui-se haver uma de três condutas a impor: 1 . Avaliação da quota de iodo alimentar das populações, ou 2. Medida do iodo urinário, prévia a rastreamento/tratamento, ou 3. DRI. A dificuldade técnica, na medida da iodúria, foi em parte aparentemente sanada, através de teste rápido não dispendioso para medir iodeto urinário, recentemente relatado.

Assim, em países como o Brasil, em que se ignora a quota alimentar de iodo, impõe-se ora a prescrição de DRI, ora medida de iodúria, que pode indicar a necessidade da DRI. A criação do novo teste veio simplificar a conduta. Afora a exigência de urina fresca, a limitação é não identificarem-se outros sais, senão iodetos, pelo método. Resta saber $\mathrm{cm}$ que grau e freqüência, outros diferentes sais ocorrem, na contaminação, para decidir a validade do teste.

\section{AGRADECIMENTOS}

A Adalgisa Schröder c Desirée Sebben, da biblioteca da FFFCPMA, por incansável contribuição, nas consultas a Medline c LILACS; a Nara Regina Ferreira, pela paciência em bater e rebater o manuscrito; ao Prof. Hugo R. K. Lisboa, pela cessão de sua excelente 
tese de mestrado; e, last not least, à Prof. Carolina A. Moreira Kulak, pela presteza em obter bibliografia indispensável, na biblioteca da Columbia University, Novia Iorque.

\section{REFERÊNCIAS}

1. Maloof F, Vickery AL, Rapp B. Evaluation of various factors influencing treatment of metastatic thyroid carcinoma with $1^{131}$. J Clin Endocrinol Metab 1956; 16: 7-27.

2. Beierwaltes $W H$. The treatment of thyroid carcinoma with radioactive lodine. Semin Nucl Med 1978; 8: 79-94.

3. Mazzaferri EL, Young RL, Oertel JE, Kemmerer WT, Page CP. Papillary thyroid carcinoma: the impact of therapy in 576 patients. Medicine 1977; 56: 171-96.

4. Mazzaferri EL, Young RL. Papillary thyroid carcinoma: a 10-year follow-up report on the impact of therapy in 576 patients. Am J Med 1981; 70: 51 1-8.

5. Wong JB, Kaplan MM, Meyer KB, Pauker SG. Ablative radioactive iodine therapy for apparently localized thyroid carcinoma. A decision analytic perspective. Endocrinol Metab Clin North Am 1990; 19: 741-60.

6. Harbert JC. Radioiodine therapy of differentiated thyroid carcinoma: and Appendix D: Low-iodine diet. In: Harbert JC, editor. Nuclear Medicine Therapy. New York: Thieme, 1987: 50, 307-8.

7. Hurley JR, Becker DV. Treatment of thyroid carcinoma with radioiodine. In: Goltschalk A, Hoffer PA, Potchen EJ, Berger HJ, editors. Diagnostic Nuclear Medicine. 2nd ed Baltimore: Williams \& Wilkins, 1988: 792-814.

8. Simpson WJ, Panzarella T, Carruthers JS, Gospodarowicz MK. Sutcliffe SB. Papillary and follicular thyroid cancer: impact of treatment in 1578 patients. Int J Radiat Oncol Biol Phys 1988; 14: 1063-75.

9. Tubiana M. Editorial: Role of radiolodine in the treatment of local thyroid cancer. Int J Radiat Oncol Biol Phys 1996; 36: $263-5$

10. Freitas JE, Gross MD, Ripley S, Shapiro B. Radionuclide diagnosis and therapy of thyroid cancer: current status report. Sem Nucl Med 1985; 25: 106-31.

11. Hay ID. Papillary thyroid carcinoma. Endocrinol Metab Clin North Am 1990; 19: 545-76.

12. Leeper RD. Shimaoka K. Treatment of metastatic thyroid cancer. Clin Endocrinol Metab 1980; 9: 383-404.

13. De Groot L. Thyroid neoplasia. In: De Groot L, editor. Endocrinology volume I. 3rd ed. Philadelphia: Saunders 1995; 848-51.

14. Meier CA, Braverman LE, Ebner SA, Veronikis I, Daniels GH. Ross DS et al. Diagnostic use of recombinant human thyrotropin in patients with thyroid carcinoma (Phase I/II study). J Clin Endocrinol Metab 1994; 78: 188-96.

15. Ladenson PW, Braverman LE, Mazzaferri EL, BruckerDavis F, Cooper DS, Garber JR et al. Comparison of administration of recombinant human thyrotropin with withdrawal of thyroid hormone for radioactive iodine scanning in patients with thyroid carcinoma. $\mathbf{N}$ Engl J Med 1997; 337: 888-96.
16. Park S-G, Reynolds JC, Brucker-Davis F, Whatley M. McEllin K, Maxted D et al. lodine kinetics during ${ }^{131}$ scanning in patients with thyroid cancer: comparison of studies with recombinant human TSH (rhTSH) vs. hypothyroidism. J Nucl Med 1996; 37:15P

17. Ringel MD, Ladenson PW. Diagnostic accuracy of 131-I scanning with recombinant human thyrotropin versus thyroid hormone withdrawal in a patient with metastatic thyroid carcinoma and hypopituitarism. J Clin Endocrinol Metab 1996; 81: 1724-5.

18. Rudavsky AZ, Freeman LM. Treatment of scan-negative, thyroglobulin-positive metastatic thyroid cancer using radioiodine ${ }^{131} \mid$ and recombinant human thyroid stimulating hormone. J Clin Endocrinol Metab 1997; 82: 11-14.

19. Emerson CH, Colzani R, Braverman LE. Editorial: epithelial cell thyroid cancer and thyroid stimulating hormone when less is more. J Clin Endocrinol Metab 1997; 82: 9-10.

20. Leeper R. Controversies in the treatment of thyroid cancer: The New York Memorial Hospital approach. Thyroid Today 1982; 5: 1-4.

21. Benua RS, Cicale NR, Sonenberg $M$, Rawson RW. The relation of radioiodine dosimetry to results and complications in the treatment of metastatic thyroid cancer. Am J Roenigenol 1962; 87: 171-82.

22. Nemec J, Röhling S, Zamrazil V, Pohunková D. Comparison of the distribution of diagnostic and thyroablative ${ }^{13 /}$ in the evaluation of differentiated thyroid cancers. J Nucl Med 1979; 20: 92-97.

23. Pineda JD, Lee T, Ain K, Reynolds JC, Robbins J. lodine131 therapy for thyroid cancer patients with elevated thyroglobulin and negative diagnostic scan. J Clin Endocrinol Metab 1995; 80: 1488-92

24. Maxon HR, Smith HS. Radioiodine-131 in the diagnosis and treatment of metastatic well differentiated thyroid cancer. Endocrinol Melab Clin N Am 1990; 19: 685-718.

25. Keston AJ, Ball RP. Frantz VK. Palmer WW. Storage of radioactive iodine in a metastasis from thyroid carcinoma. Science 1942; 95: 362-3.

26. Seidlin SM, Marinelli LD. Oshry E. Radioactive iodine therapy. Effect on functioning metastases of adenocarcinoma of the thyroid. JAMA 1946; 132: 838-47.

27. Blahd WH. Treatment of malignant thyroid disease. Semin Nucl Med 1979; 9: 95-9.

28. Hamburger Jl. Diuretic augmentation of ${ }^{13} /$ uptake in inoperable thyroid cancer. N Engl J Med 1969; 280: 1091-4.

29. Lakshmanan M. Schaffer A, Robbins J, Reynolds J, Norton $\mathrm{J}$. A simplified low iodine diet in 1311 scanning and therapy of thyroid cancer. Clin Nucl Med 1988; 13: 866-8.

30. Crile $G$, Jr. Endocrine dependency of certain thyroid cancers and danger that hypothyroidism may stimulate their growth. Cancer 1957; 10: 1119-37.

31. Hamburger JI, Desai P. Mannitol augmentation of ${ }^{131}$ uptake in treatment of thyroid carcinoma. Metabolism 1966; 15: 1055-8.

32. Barakat RM, Ingbar SH. The effect of acute iodine depletion on thyroid function in man. J Clin Invest 1965; 44: 1777-24.

33. Beyer KH, Jr. ,Fehr DM, Gelarden RT, White WJ, Lang CM, Vesell ES. Hydrochlorothiazide-induced ${ }^{131}$ excretion 
facilitated by salt and water. J Clin Pharmacol 1981; 21: 201-12.

34. Maruca J, Santner S, Miller K, Santer RJ. Prolonged iodine clearance with a depletion regimen for thyroid carcinoma. J Nucl Med 1984; 25: 1089-93.

35. Goslings BM. Effect of a low iodine diet on ${ }^{13} \mid$ therapy in follicular thyroid carcinomata. J Endocrinol 1975; 64: 30P.

36. Maxon HR, Thomas SR, Boehringer A, Drilling J, Sperling MI, Sparks JC et al. Low iodine diet in ${ }^{|3|} \mid$ ablation of thyroid remnants. Clin Nucl Med 1983; 8: 123-6.

37. Ain KB, Dewitt PA, Gardner TG, Berryman SW. Low-iodine tube-feeding diet for iodine-131 scanning and therapy. Clin Nucl Med 1994; 19: 504-7.

38. Oddie TH, Pirnique FG. Fisher DA, Meade JH, Jr. Geografic variation of radioiodine uptake in euthyroid subjects. $\mathrm{J}$ Clin Endocrinol Metab 1968; 28: 761-75.

39. Pittman JA, Jr., Dailey GE, III, Beschi RJ. Changing normal values for thyroidal radioiodine uptake. $N$ Engl J Med 1969; 280: 1431-4.

40. Oddie TH, Fisher DA, McConahey WM, Thomson CS. lodine intake in the United States: a reassessment. J Clin Endocrinol Metab 1970; 30: 659-65.

41. Sachs BA, Siegel E. Horvitt BN, Siegel E. Bread iodine content and thyroid radioiodine uptake: a tale of two cities. Br Med J 1972; 1: 79-81.

42. London WT, Vought RL, Brown FA. Brief recording: bread - a dietary source of large quantities of iodine. $N$ Engl J Med 1965; 273: 381.

43. Hemken RW, Vandersall JH. Oskarsson MA, Fryman LR. lodine intake related to milk iodine and performance of dairy cattle. J Dairy Sci 1972; 55: 931-4.

44. Vought RL, Brown FA, Wolff J. Erythrosine: an adventitions source of iodide. J Clin Endocrinol Metab 1972; 34: 747-52.

45. Kidd PS, Trowbridge FL, Goldsby JB, Nichanan MZ. Sources of dietary iodine. J Am Diel Assoc 1974; 65: 420-2.

46. Park YK, Harland BF, Vanderveen JE, Shank FR, Prosky L. Estimation of dietary iodine intake of Americans in recent years. J Am Diet Assoc 1981; 79: 17-24.

47. Allegrini M, Pennington JAT, Tanner JT. Total diet study: determination of iodine intake by neutron activation analysis. J Am Diet Assoc 1983; 83: 18-24.

48. Dellavalle ME, Barbano DM. lodine content of milk and other foods. J Food Prot 1984; 47: 678-84

49. Pennington JAT, Wilson DB, Newell RF, Harland BF, Johnson RD, Vanderveen JE. Selected minerals in food surveys, 1974 to 1981/2. J Am Diet Assoc 1984; 84: 771-80.

50. Haas S. Contamination of protein-bound iodine by pink gelatin capsules colored with erythrosine. Ann Intern Med 1970; 72: 549-52.

51. Stanbury JB. The changing iodide-uptake test. N Engl J Med 1969; 280: 1474-5.

52. Alazraki NP, Halpern SE, Ashburn WL. A re-evaluation of ${ }^{131}$ thyroid uptakes. Radiology 1972; 105: 611-4.

53. Robertson JS, Nolan NG, Wahner HW, McConahey WM. Thyroid radioiodine uptakes and scans in euthyroid patients. Mayo Clin Proc 1975; 50: 79-84.
54. Koutras DA, Alexander WD, McG Harden R, Wayne E Effect of small iodine supplements on thyroid function in normal individuals. J Clin Endocrinol Metab 1964; 24:857-62.

55. Oddie TH, Meade JH, Jr., Fisher DA. Dependence of thyroidal clearance rate on plasma iodine level. J Clin Endocrinol Metab 1967; 27: 722-7.

56. Cavalieri RR, MCDougall IR. In vivo isotopic tests and imaging. In: Braverman LE and Utiger RD, editors. Werner and Ingbar's The Thyroid. 7th ed. Philadelphia: Lippincott-Raven, 1996: 355.

57. Pineda JD. Lee T, Robbins J. Treating metastatic thyroid cancer. The Endocrinologist 1993; 3:433-42.

58. Mazzaferri EL. Treatment of carcinoma of follicular epithelium. In: Ingbar SH, Braverman LE, editors. Werner's The Thyroid. 5th ed. Philadelphia: Lippincott, 1986: 1342-3.

59. Edmonds CJ. Treatment of thyroid cancer. Clin Endocrinol Metab 1979; 8: 223-42.

60. Delange FM, Ermans A-M. Intrinsic and extrinsic variables: iodine deficiency. In: Braverman LE and Utiger RD, editors. Werner and Ingbar's The Thyroid. 7th ed. Philadelphia: Lippincott-Raven, 1996: 296-316.

61. Pennington JAT. Bowes \& Church's Food Values of Portions Commonly Used. $15^{\text {th }}$ ed. Philadelphia: Lippincott. 1989: 264 .

62. Holland B, Welch AA, Unwin JD, Buss DH, Paul AA, Southgate DAT. McCance and Widdowson's The composition of foods. 5th ed. Cambridge: The Roval Society of Chemistry and Ministry of Agriculture, Fisheries and Food. 1991: 110.

63. Lubin E, Mechlis-Frish S, Zatz S, Shimoni A, Segal K, Avraham $A$ et al. Serum thyroglobulin and iodine-131 wholebody scan in the diagnosis and assessment of treatment for metastatic differentiated thyroid carcinoma. J Nucl Med 1994; 35: 257-62

64. Maxon HR, Thomas SR, Hertzberg VS, Kereiakes JG, Chen I-W, Sperling $\mathrm{Ml}$ et al. Relation between radiation dose and outcome of radioiodine therapy for thyroid cancer. N Engl J Med 1983; 309: 937-41

65. Maxon HR III, Englaro EE, Thomas SR, Hertzberg VS, Hinnefeld JD. Chen LS et al. Radioiodine-131 therapy for well-differentiated thyroid cancer - a quantitative radiation dosimetric approach: outcome and validation in 85 patients. J Nucl Med 1992; 33:1 132-6.

66. Bushnell DL, Boles MA, Kaufman GE, Wadas MA. Barnes WE. Complications, sequela and dosimetry of iodine-131 therapy for thyroid carcinoma. J Nucl Med 1992; 33:2214-21.

67. Mazzaferri EL. Carcinoma of follicular epithelium: radioiodine and other treatments and outcomes. In: Braverman LE and Utiger RD, editors. Werner and Ingbar's The Thyroid. 7th ed. Philadelphia: LippincottRaven, 1996: 922-45.

68. Saxena KM, Chapman EM, Pryles CV. Minimal dosage of iodide required to suppress uptake of iodine-131 by normal thyroid. Science 1962; 138: 430-1.

69. Garber DW, Henkin Y, Osteriund LC, Woolley TW, Segrest JP. Thyroid function and other clinical chemistry parameters in subjects eating iodine-enriched eggs. Food Chem Toxicol 1993; 31: 247-51 
70. Pennington JAT, Schoen SA. Contributions of food groups to estimated intakes of nutritional elements: results from the FDA total diet studies, 1982-1991. Internat J Vit Nutr Res 1996; 66:342-9.

71. Pennington JAT, Schoen SA. Total diet study: estimated dietary intakes of nutritional elements, 1982-1991. Internat J Vit Nutr Res 1996; 66: 350-62.

72. Food and Nutrition Board, National Academy of Sciences (1989) Recommended Dietary Allowances. 10th rev, ed.Washington DC: National Academy Press.

73. Kuni CC. Klingensmith WC, III. Failure of low doses of ${ }^{131}$ to ablate residual thyroid tissue following surgery for thyroid cancer. Radiology 1980; 137: 773-4.

74. Maheshwari YK, Stratton Hill C, Jr., Haynie TP, III, Hickey RC. Samaan NA. ${ }^{131}$ therapy in differentiated thyroid carcinoma: M.D. Anderson Hospital Experience. Cancer 1981; 47: 664-71.

75. Samaan NA, Schultz PN, Haynie TP, Ordonez NG. Pulmonary metastases of differentiated thyroid carcinoma: treatment results in 101 patients. J Clin Endocrinol Metab 1985; 65: 376-80

76. Ruegemer JJ, Hay ID, Bergstralh EJ, Ryan JJ, Offord KP. Gorman CA. Distant metastases in differentiated thyroid carcinoma: a multivariate analysis of prognostic variables. J Clin Endocrinol Metab 1988; 67:501-8.

77. Brennan MD, Bergstralh EJ, van Herden JA, McConahey WM. Follicular thyroid cancer treated at the Mayo Clinic, 1946 through 1970: Initial manifestations, pathologic findings, therapy, and outcome. Mayo Clin Proc 1991; 66: 11-22.

78. Beierwaltes WH, Nishiyama RH, Thompson NW, Copp JE, Kubo A. Survival time and "cure" in papillary and follicular thyroid carcinoma with distant metastases: statistics following University of Michigan therapy. J Nucl Med 1982; 23: $561-8$.

79. Paryani SB, Chobe RJ, Scott W, Wells J, Jr., Johnson D. Kuruvilla $A$ et al. Management of thyroid carcinoma with radioactive ${ }^{131}$. Int J Radiat Oncol Biol Phys 1996; 36: 83-6.

80. DeGroot LJ, Kaplan EL, McCormick M, Straus FH. Natural history, treatment, and course of papillary thyroid carcinoma. J Clin Endocrinol Metab 1990; 71: 414-24.

81. Samaan NA, Schultz PN, Hickey RC, Goepfert H, Haynie TP, Johnston DA et al. The results of various modalities of treatment of well differentiated thyroid carcinoma: a retrospective review of 1599 patients. J Clin Endocrinol Metab 1992; 75: 714-20.

82. Sherman SI, Tielens ET, Sostre S, Wharan MD, Jr., Ladenson PW. Clinical utility of posttreatment radioidine scans in the management of patients with thyroid carcinoma. $\mathrm{J}$ Clin Endocrinol Metab 1994; 78: 629-34.

83. Lorberboym M, Murthy S, Mechanick Jl, Bergman D, Morris JC, Kim CK. Thallium-201 and iodine-131 scintigraphy in differentiated thyroid carcinoma. J Nucl Med 1996; 37: 1487-91.

84. Park H-M. Stunned thyroid after high-dose ${ }^{131} 1$ imaging. Clin Nucl Med 1992; 17: 501-2.

85. Park H-M, Perkins OW, Edmondson JW, Schnute RB, Manatunga $A$. Influence of diagnostic radioiodines on the uptake of ablative dose of iodine-131. Thyroid 1994; 4:49-54
86. Spencer CA, Wang C-C. Thyroglobulin measurement techniques, clinical benefits, and pitfalls. Endocrinol Metab Clin North Am 1995; 24: 841-63.

87. Hay ID, Grebe SKG. What's new in the management of differentiated thyroid cancer? in: Jameson JL. Program Director, and Molitch ME, Co-Program Director, The Endocrine Sociely's Clinical Endocrinology Update'96 Syllabus. Bethesda:The Endocrine Society, 1996: 246.

88. Grebe SKG, Hay ID. Follicular thyroid cancer. Endocrinol Melab Clin North Am 1995; 24:761-801.

89. Korff JM, DeGroot LJ. The management of radiationinduced tumours of the thyroid. Clin Endocrinol Metab $1981 ; 10: 299-315$.

90. Solomon BL, Wartofsky L, Burman KD. Current trends in the management of well differentiated papillary thyroid carcinoma. J Clin Endocrinol Metab 1996; 81: 333-9.

91. Ingbar SH. The thyroid gland. In: Wilson JD, Foster DW editors. Williams Textbook of Endocrinology. 7th ed. Philadelphia: Saunders, 1985: 804-5.

92. Larsen PR, Ingbar SH. The thyroid gland. In: Wilson JD, Foster DW, editors. Williams Textbook of Endocrinology. 8th ed. Philadelphia: Saunders, 1992: 474.

93. Cavalieri RR. Radioiodine in diagnosis \& therapy. In: Dillmann WH, Program Director, The Endocrine Society's Clinical Endocrinology Update'95 Syllabus. Bethesda:The Endocrine Society, 1995: 149.

94. Ain KB. Papillary thyroid carcinoma. Endocr Metab Clin North Am 1995; 24: $711-60$.

95. Sweeney DC, Johnston GS. Radioiodine therapy for thyroid cancer. Endocrinol Metab Clin North Am 1995; 24: 803-39.

96. Baldet L, Manderscheid J-C. Glinoer D, Jaffiol C, CosteSeignovert B, Percheron $C$. The management of differentiated thyroid cancer in Europe in 1988. Results of an international survey. Acta Endocrinol (Copenh) 1989; 120: $547-58$

97. Rubello D, Casara D. Girelii ME, Piccolo M, Busnardo B. Clinical meaning of circulating antithyroglobulin antibodies in differentiated thyroid cancer: a prospective study. J Nucl Med 1992; 33: 1478-80.

98. Casara D, Rubello D, Saladini G, Masarotto G, Favero A, Girelli ME et al. Different features of pulmonary metastases in differentiated thyroid cancer: natural history and multivariate statistical analysis of prognostic variables. J Nucl Med 1993; 34: 1626-31.

99. Dottorini M. Lomuscio $G$, Mazzuchelli L.Vignati A, Colombo L. Assessment of female fertility and carcinogenesis after iodine-131 therapy for differentiated thyroid carcinoma. J Nucl Med 1995; 36:21-7.

100. Pacini F, Cetani F, Miccoli P, Mancusi F, Ceccarelli $C$, Lippi $F$ et al Outcome of 309 patients with metastatic differentiated thyroid carcinoma treated with radioiodine. World J Surg 1994; 18:600-4.

101. Muratet J-P, Giraud P. Daver A, Minier J.F, Gamelin E, Larra $F$. Predicting the efficacy of first iodine-131 treatment in differentiated thyroid carcinoma. J Nucl Med 1997; 38: 1362-8.

102. Proye CAG, Dromer DHR, Carnaille BM, Gontier AJP. Goropoulos A, Carpentier $P$ et al, Is it still worth while to 
treat bone metastases from differentiated thyroid carcinoma with radioactive iodine? World J Surg 1992; 16: 640-6.

103. Pujol P. Daures J-P. Nsakala N, Baldet L, Bringer J, Jaffiol C. Degree of thyrotropin suppression as a prognostic determinant in differentiated thyroid cancer. J Clin Endocrinol Metab 1996; 81:4318-23.

104. Schlumberger $M$, Tubiana $M$, de Vathaire $F$, Hill $C$. Gardet P. Travagli J-P et al. Long-term results of treatment of 283 patients with lung and bone metastases from differentiated thyroid carcinoma. J Clin Endocrinol Metab 1986; 63: 960-7.

105. Schlumberger M, Challeton C, De Vathaire F, Travagli JP. Gardet P, Lumbroso J-D et al. Radioactive iodine treatment and external radiotherapy for lung and bone metastases from thyroid carcinoma. J Nucl Med 1996; 37: 598-605.

106. Harder $W$, Lind $P$. Thallium-201 uptake with negative iodine-131 scintigraphy and serum thyroglobulin in metastatic oxyphilic papillary thyroid carcinoma. J Nucl Med 1998; 39:236-8.

107. Lerch H. Schober O. Kuwert T, Saur H-B. Survival of differentiated thyroid carcinoma studied in 500 patients. $J$ Clin Oncol 1997; 15: 2067-75.

108. Grünwald F, Menzel C, Fimmers R, Zamora PO, Biersack $\mathrm{HJ}$. Prognostic value of thyroglobulin after thyroidectomy before ablative radioiodine therapy in thyroid cancer. J Nucl Med 1996; 37:1962-70.

109. Menzel C. Grünwald F, Schomburg A, Palmedo H, Bender H. Späth $G$ et al. "High-dose" radioiodine therapy in advanced differentiated thyroid carcinoma. J Nucl Med 1996; 37:1496-1503.

110. Phlips P, Hanzen C, Andry $G$, Van Houtte P. Früung J. Posoperative irradiation for thyroid cancer. Eur J Surg Oncol 1993; 19: 399-404.

111. Hardy KJ, Walker BR, Lindsay RS, Kennedy RL., Seck JR, Padfield PL. Thyroid cancer management. Clin Endocrinol (OXf) 1995; 42: 651-5.

112. Laurberg P. Editorial: iodine intake - what are we aiming at? J Clin Endocrinol Metab 1994; 79; 17-9.

113. Davis NL, Gordon M, Germann E, McGregor Gl, Robins RE. Efficacy of ${ }^{131}$ ablation following thyroidectomy in patients with invasive follicular thyroid cancer. Am J Surg 1992; 163: 472-5.

114. Comtois R, Thériault C, Del Vecchio P. Assessment of the efficacy of iodine-131 for thyroid ablation. J Nucl Med 1993; 34:1927-30.

115. Pasieka JL, Rotstein LE. Consensus conference on welldifferentiated thyroid cancer: a summary. Can J Surg 1993; 36: 298-301.

116. Watanabe N, Yokoyama K, Kinuya S, Shuke N, Shimizu M. Futatsuya R el al. Radiotoxicity after iodine-131 ther- apy for thyroid cancer using the micronucleus assay. J Nucl Med 1998; 39: 436-40.

117. Nakada K, Morita K, Shiga T, Kaji T, Kanegae K, Tsukamoto E ef al. Is small dose radioiodine scintigraphy reliable in detecting metastatic fumors from differentiated thyroid carcinoma? J Nucl Med 1998; 39(suppl): 26lP.

1 18. Kim YK, Chung J-K, Lee DS, Jeong JM, Lee MC, Cho BY et al. Ablation dose of ${ }^{131} 1$ for remnant thyroid tissue in patients with posoperative thyroid cancer of high iodine intake population. J Nucl Med 1998; 39(suppl): 261P.

119. Suzuki H, Higuchi T, Sawa K, Ontaki S, Horiuchi Y. Endemic coast goitre in Hokkaido, Japan. Acta Endocrinol (Copenh) 1965; 50: 161-76.

120. Bianchi R, lervasi $G$, Matteucci F, Turchi S, Cazzuola F, Bellina $C R$ et al. Chromatographic identification in serum of endogenously radioiodinated thyroid hormones after iodine-131 whole-body scintigraphy in the follow-up of patients with differentiated thyroid carcinoma. J Nucl Med 1993; 34: 2032-7.

121. Roelants $V$, De Nayer P, Bouckaert A, Beckers C. The predictive value of serum thyroglobulin in the follow-up of differentiated thyroid cancer. Eur J Nucl Med $1997 ; 24: 722-7$.

122. Yen T-C. King K-L, Yang A-H, Liu R-S, Yeh SH. Comparative radionuclide imaging of metastatic insular carcinoma of the thyroid: value of technetium-99m-(V)DMSA. J Nucl Med 1996; 37: 78-80.

123. Gross JL, Furlanetto TW, Kruter RHE, Denardin OVP, de Castro JAS, Hutz A. Características clínicas e laboratoriais das doenças da tireóide. Arq Bras Endocrinol Metab 1983; 27: 89-94.

124. de Almeida JS, Biegler RS, Coutinho LMB. Freqüência das neoplasias malignas primárias da tireóide. $\mathbf{R}$. AMRIGS 1988; 32: 237-42.

125. Medeiros-Neto $G$. Alteraçōes cerebrais fetais e carência de iodo. Arq Bras Endocrinol Metab 1993; 37: 100-1.

126. Lisboa HRK. Prevalência de bócio entre estudantes prépuberais em Passo Fundo, Rio Grande do Sul. Tese de Mestrado. UFRGS. 1994: 33-45.

127. Rendi J, Bier D, Groh T, Reiners C. Rapid urinary iodide test. J Clin Endocrinol Melab 1998; 83: 1007-12

Endereço para correspondência:

Henry Wolf

Rua Mostardeiro, 257/apto 401

90430-180 Porto Alegre. RS

Fax:(051) 222-813 